\title{
Analisa Pengendalian Kualitas Refined Bleached Deodorized Palm Oil Dengan Menggunakan Metode Taguchi Pada PT. XYZ
}

\author{
Yuana Delvika
}

Program Studi Teknik Industri, Fakultas Teknik, Universitas Medan Area

Email : yuana_delvika@yahoo.com

\begin{abstract}
Abstrak
PT. XYZ merupakan perusahaan yang bergerak di bidang pengolahan kelapa sawit. Di dalam pengolahan dari CPO menjadi minyak Refined Bleached Deodorized Palm Oil, tentunya tidak lepas dari masalah yang berhubungan dengan kualitas. Penelitian terhadap kualitas Refined Bleached Deodorized Palm Oil dilakukan dengan menggunakan Metode Taguchi. Tujuan dari metode Taguchi ini yaitu untuk menentukan kombinasi level yang optimal untuk masingmasing faktor sehingga dihasilkan Refined Bleached Deodorized Palm Oil yang sesuai dengan standar. Hasil analisa diolah dengan menggunakan metode rata-rata, analisis varians dan strategi pooling up. Dari hasil kesimpulan menunjukkan bahwa untuk kadar ALB setting yang paling optimal yaitu tekanan perebusan pada level 1 (2,0 torr), temperatur perebusan pada level $2\left(105^{\circ} \mathrm{C}\right)$ dan waktu pada proses perebusan pada level 1 (50 min). Untuk kadar warna setting yang paling optimal yaitu tekanan perebusan pada level 1 (2,0 torr), temperatur perebusan pada level $2\left(105^{\circ} \mathrm{C}\right)$ dan waktu pada proses perebusan pada level 1 (50 min). Sedangkan untuk kadar air setting yang paling optimal yaitu waktu pada proses perebusan pada level $2(60 \mathrm{~min})$, temperatur perebusan pada level $2\left(105^{\circ} \mathrm{C}\right)$ dan tekanan pada perebusan (2,0 torr). Berdasarkan data di atas, dapat diketahui bahwa total proporsi cacat secara keseluruhan setelah diterapkan kombinasi setting yang optimal berdasarkan penelitian dengan metode Taguchi adalah 18,05\%. Setelah menerapkan kombinasi setting yang optimal berdasarkan metode Taguchi, total proporsi cacat secara keseluruhan menurun sebesar 9,71\%.

Kata kunci : Frekuensi Cacat, Metode Taguchi, Pengendalian Kualitas, Refined Bleached Deodorized Palm Oil

Abstract

PT. XYZ is a company runs in the field of processing crude palm oil (CPO). Also, a quality control of processing CPO into Refined Bleached Deodorized Palm Oil is crucial and should be handled in forward. The study employs Taguchi Method to determine the optimal combination level for each factor to generate a standard variety of Refined Bleached Deodorized Palm Oil. Several methods are used to analyze the result, namely means, variance analysis, dan pooling up strategy. The result reveals that an optimal ALB content setting is at level 1 (2.0 torr) in boiling pressure, boiling temperature is at level $2\left(105^{\circ} \mathrm{C}\right)$ and the boiling period is at level 1 (50 mins). Then, the optimal color content setting is at level 1 (2.0 torr) in boiling pressure, boiling temperature is at level $2\left(105^{0} \mathrm{C}\right)$ and the boiling period is at level 1 (50 mins). Meanwhile, the water content has the optimal setting at level 2 (60 mins) in boiling period, boiling temperature is at level $2\left(105^{\circ} \mathrm{C}\right)$ and boiling pressure is 2.0 torr. To conclude, after applying the optimal combination setting, the total number of defects is as much as $18.05 \%$ in accordance with Taguchi Method. Then, overall numbers of defects were decreases as much as $9.71 \%$.
\end{abstract}

Keywords: Frequency Disability, Quality Control, Refined Bleached Deodorized Palm Oil, Taguchi Method 


\section{PENDAHULUAN}

Pemahaman kualitas sangat penting dalam pengembangan aktifitas perusahaan sebab pertumbuhan suatu perusahaan sangat ditentukan oleh kualitas produk atau jasa yang dihasilkan. Kurangnya pemeliharaan terhadap kualitas akan menyebabkan terjadinya kehilangan peluang menjual produk dan pangsa pasar yang akhirnya berakibat pada penurunan aktifitas dan produktivitas perusahaan. PT. XYZ merupakan perusahaan yang memproduksi minyak Refined Bleached Deodorized Palm Oil. Faktor-faktor yang menentukan kualitas Refined Bleached Deodorized Palm Oil yaitu, kadar asam lemak bebas, kadar air dan warna. Dari uraian di atas, maka perlu dilakukan penelitian untuk mengetahui faktor-faktor yang mempengaruhi kualitas Refined Bleached Deodorized Palm Oil dan cara penanggulangannya agar kualitas minyak sawit yang di produksi dapat memenuhi standar yang telah ditetapkan. Keadaan saat ini menunjukkan dalam pengolahan minyak sawit, kualitas yang dihasilkan ternyata selalu bervariasi dan sering tidak memenuhi spesifikasi standar mutu atau kualitas yang diterapkan perusahaan.

\section{METODE PENELITIAN}

Penelitian diawali dengan peninjauan dan pengumpulan data di PT. XYZ . Data yang diambil adalah data Kadar asam, warna dan Kadar air pada minyak Refined Bleached Deodorized Palm Oil. Data tersebut diperoleh dengan melakukan kegiatan tanya jawab dan wawancara dengan operator, supervisor, dan laboratorium secara langsung dilapangan dan mencatat dari dokumen yang terdapat di perusahaan. Adapun Langkah-langkah dalam metode taguchi ini dibagi menjadi tiga fase utama yang meliputi keseluruhan pendekatan eksperimen. Tiga fase tersebut adalah fase perencanaan, fase pelaksanaan dan fase analisis. Fase perencanaan merupakan fase yang paling penting dari eksperimen untuk menyediakan informasi yang diharapkan. Fase perencanaan adalah ketikafaktor dan levelnya dipilih. Oleh karena itu, merupakan langkah yang terpenting dalam eksperimen. Fase terpenting kedua adalah fase pelaksanaan, ketika hasil eksperimen telah didapatkan. Jika eksperimen direncanakan dan dilaksanakan dengan baik, analisis akan lebih mudah dan cenderung untuk dapat menghasilkan infomasi yang positif tentang faktor dan level. Fase analisis adalah ketika informasi positif atau negatif berkaitan dengan faktor dan level yang telah dipilih dihasilkan berdasarkan dua fase sebelumnya. Fase analisis adalah hal penting terakhir yang mana apakah peneliti akan dapat menghasilkan hasil yang positif. 
HASIL DAN PEMBAHASAN

Adapun cara teknik pengolahan data yang digunakan adalah sebagai berikut :

1. Perencanaan Eksperimen Dengan Metode Taguchi, Identifikasi aktor kualitas terhadap cacat, Penentuan variable Terikat, Penentuan variabel bebas, Penentuan jumlah level dan nilai level factor, Perhitungan derajat kebebasan, Pemilihan matriks orthogonal, Penugasan faktor pada kolom orthogonal array

2. Pelaksanaan Eksperimen Taguchi Untuk setiap kadar yang berpengaruh terhadap kualitas yaitu, Perhitungan Efek Faktor Utama (main effect), Perhitungan dengan average method, Perhitungan dengan S/N ratio, Perhitungan ANOVA, Strategi

3. Pooling Up, Pooling parsial I, Pooling parsial II.

Dalam percobaan ini diambil setting 12 kali produksi untuk setiap eksperimen. Dari data hasil percobaan dikelompokkan berdasarkan kategori accept dan reject.

Salah satu perhitungan dari faktor yang mempengaruhi kualitas Refined Bleached Deodorized Palm Oil.
Tabel 1. Hasil Percobaan Terhadap Kadar

ALB

Matriks Orthogonal $\mathrm{L}_{4}\left(2^{3}\right)$

\begin{tabular}{|c|c|c|c|c|c|}
\hline \multirow[t]{2}{*}{ Eksperimen } & \multicolumn{3}{|c|}{ Faktor } & \multirow[t]{2}{*}{ Accept } & \multirow[t]{2}{*}{ Reject } \\
\hline & & B & & & \\
\hline 1 & 1 & 1 & 1 & 8 & 4 \\
\hline 2 & 1 & 2 & 2 & 8 & 4 \\
\hline 3 & 2 & 1 & 2 & 6 & 6 \\
\hline 4 & 2 & 2 & 1 & 8 & 4 \\
\hline
\end{tabular}

Sumber : pengolahan data

1. Perhitungan Efek Faktor Utama (Main Effect)

a. Perhitungan Dengan Average Method

Perhitungan rata-rata tiap level faktor adalah :

$$
\begin{aligned}
\mathrm{A}_{1}=\frac{Y_{1}+Y_{2}}{2}=\frac{4+4}{2}=4 \\
\mathrm{~A}_{2}=\frac{Y_{3}+Y_{4}}{2}=\frac{6+4}{2}=5
\end{aligned}
$$$$
\mathrm{B}_{1}=\frac{Y_{1}+Y_{3}}{2}=\frac{4+6}{2}=5
$$

$$
\mathrm{B}_{2}=\frac{Y_{2}+Y_{4}}{2}=\frac{4+4}{2}=4
$$

$$
\begin{gathered}
\mathrm{C}_{1}=\frac{Y_{1}+Y_{4}}{2}=\frac{4+4}{2}=4 \\
\mathrm{C}_{2}=\frac{Y_{2}+Y_{3}}{2}=\frac{4+6}{2}=5
\end{gathered}
$$

Sehingga diperoleh peringkat faktor seperti tabel 2 di bawah ini

Tabel 2. Peringkat Faktor Berdasarkan Average 


\begin{tabular}{clccc}
\hline \multicolumn{5}{c}{ Faktor } \\
\hline \multirow{3}{*}{ Eksperimen } & A & B & C & \\
& 1 & 2 & 3 & \\
& 1 & 1 & 1 & $-12,041$ \\
1 & 1 & 2 & 2 & $-12,041$ \\
2 & 2 & 1 & 2 & $-15,56$ \\
3 & 2 & 2 & 1 & $-12,041$ \\
\hline
\end{tabular}

Sumber : pengolahan data

b. Perhitungan Dengan S/N Ratio

Karakteristik yang digunakan adalah Smaller the Better, maka S/N Ratio digunakan pada katergori reject.

Untuk MSD dihitung untuk setiap respon eksperimen sehingga ada 4 nilai MSD, yaitu :

$$
\begin{aligned}
& \operatorname{MSD}_{1}=4^{2}=16 \\
& \operatorname{MSD}_{2}=4^{2}=16 \\
& \operatorname{MSD}_{3}=6^{2}=36 \\
& \operatorname{MSD}_{4}=4^{2}=16
\end{aligned}
$$

Sehingga nilai $\mathrm{S} / \mathrm{N}$ dapat dihitung sebagai berikut :

$$
\begin{array}{ll}
\mathrm{S} / \mathrm{N}_{1}=-10 \log _{10}\left(\mathrm{MSD}_{1}\right) & =-12,041 \\
\mathrm{~S} / \mathrm{N}_{2}=-10 \log _{10}\left(\mathrm{MSD}_{2}\right) & =-12,041 \\
\mathrm{~S} / \mathrm{N}_{3}=-10 \log _{10}\left(\mathrm{MSD}_{3}\right) & =-15,56 \\
\mathrm{~S} / \mathrm{N}_{4}=-10 \log _{10}\left(\mathrm{MSD}_{4}\right) & =-12,041
\end{array}
$$

Sehingga diperoleh nilai $\mathrm{S} / \mathrm{N}$

Ratio seperti tabel 3 di bawah ini.

\begin{tabular}{ccccc}
\hline Faktor & \multicolumn{2}{c}{ Level } & Selisih & Ranking \\
\cline { 2 - 3 } & $\mathbf{1}$ & $\mathbf{2}$ & & \\
A & 4 & 5 & 1 & 1 \\
B & 5 & 4 & 1 & 2 \\
C & 4 & 5 & 1 & 3 \\
\hline
\end{tabular}

Tabel 3. Nilai S/N Ratio

Sumber : pengolahan data

Perhitungan rata-rata tiap level faktor adalah sebagai berikut:

$$
\mathrm{A}_{1}=\frac{Y_{1}+Y_{2}}{2}=\frac{-12,041+(-12,041)}{2}=-12,041
$$

$$
\mathrm{A}_{2}=\frac{Y_{3}+Y_{4}}{2}=\frac{-15,56+(-12,041)}{2}=-13,800
$$$$
\mathrm{B}_{1}=\frac{Y_{1}+Y_{3}}{2}=\frac{-12,041+(-15,56)}{2}=-13,800
$$$$
\mathrm{B}_{2}=\frac{Y_{2}+Y_{4}}{2}=\frac{-12,041+(-12,041)}{2}=-12,041
$$

$$
\mathrm{C}_{1}=\frac{Y_{1}+Y_{4}}{2}=\frac{-12,041+(-12,041)}{2}=-12,041
$$$$
\mathrm{C}_{2}=\frac{Y_{2}+Y_{3}}{2}=\frac{-12,041+(-15,56)}{2}=-13,800
$$

Maka diperoleh peringkat faktor seperti tabel 4 di bawah ini.

Tabel 4. Peringkat Faktor S/N Ratio

\begin{tabular}{ccccc}
\hline Faktor & \multicolumn{2}{c}{ Level } & Selisih & Ranking \\
\cline { 2 - 3 } & 1 & 2 & & \\
A & $-12,041$ & $-13,800$ & 1,759 & 1 \\
B & $-13,800$ & $-12,041$ & 1,759 & 2 \\
C & $-12,041$ & $-13,800$ & 1,759 & 3 \\
\hline
\end{tabular}


Sumber : pengolahan data

\section{Perhitungan ANOVA}

Dalam perhitungan ANOVA di bawah ini, produk dikategorikan menjadi kelas reject (I) dan kelas accept (II) karena fokus pada kategori cacat yaitu Smaller the Better. Hasil frekuensi kelas accept dan reject dapat dilihat pada tabel 5

Tabel 5. Hasil Frekuensi Kelas Accept dan Reject

\begin{tabular}{cc}
\hline \multicolumn{2}{c}{ Frekuensi } \\
\hline Reject & Accept \\
4 & 8 \\
4 & 8 \\
6 & 6 \\
4 & 8 \\
18 & 30 \\
\hline
\end{tabular}

Sumber : pengolahan data

Langkah-langkah metode perhitungan adalah sebagai berikut :

1. Rata-rata eksperimen keseluruhan

$$
\begin{aligned}
\bar{Y} & =\frac{\sum Y}{n} \\
\bar{Y} & =\frac{4+4+6+4}{4} \\
& =4,5
\end{aligned}
$$

2. Jumlah kuadrat total

$$
\begin{aligned}
\mathrm{S}_{\mathrm{T}} & =\sum Y^{2} \\
\mathrm{~S}_{\mathrm{T}} & =4^{2}+4^{2}+6^{2}+4^{2} \\
& =84
\end{aligned}
$$

3. Jumlah kuadrat karena rata-rata

$$
\begin{aligned}
\mathrm{S}_{\mathrm{m}} & =\mathrm{n} \bar{Y}^{2} \\
& =4 \times(4,5)^{2} \\
& =81
\end{aligned}
$$

4. Jumlah kuadrat karena faktor-faktor $\mathrm{S}_{\mathrm{A}}=\frac{(\text { Total A1 })^{2}}{\mathrm{nA} 1}+\frac{(\text { Total A2 })^{2}}{\mathrm{nA} 2}-$

$$
\begin{aligned}
S_{\mathrm{m}} & =\frac{(4+4)^{2}}{2}+\frac{(6+4)^{2}}{2}-81 \\
& =32+50-81 \\
& =1
\end{aligned}
$$$$
\mathrm{S}_{\mathrm{B}}=\frac{(\text { Total B1 })^{2}}{\mathrm{nB} 1}+\frac{(\text { Total B2 })^{2}}{\mathrm{nB} 2}-
$$$$
\mathrm{S}_{\mathrm{m}}=\frac{(4+6)^{2}}{2}+\frac{(4+4)^{2}}{2}-81
$$$$
=50+32-81
$$$$
=1
$$

$\mathrm{S}_{\mathrm{C}}=\frac{(\text { Total C1 })^{2}}{\mathrm{nC} 1}+\frac{(\text { Total C2 })^{2}}{\mathrm{nC} 2}-$

$$
\mathrm{S}_{\mathrm{m}}=\frac{(4+4)^{2}}{2}+\frac{(4+6)^{2}}{2}-81
$$$$
=32+50-81
$$$$
=1
$$

5. Jumlah kuadrat karena error

$$
\begin{aligned}
\mathrm{S}_{\mathrm{e}} & =\mathrm{S}_{\mathrm{T}}-\mathrm{S}_{\mathrm{A}}-\mathrm{S}_{\mathrm{B}}-\mathrm{S}_{\mathrm{C}} \\
& =84-1-1-1 \\
& =81
\end{aligned}
$$

6. Perhitungan derajat kebebasan untuk setiap faktor $\mathrm{V}_{\mathrm{A}}=($ jumlah kelas - 1) $\mathrm{x}$ (jumlah level -1)

$$
\mathrm{V}_{\mathrm{A}}=(2-1) \times(2-1)=1
$$

Untuk faktor lainnya dihitung dengan cara yang sama dengan hasil :

$$
\begin{array}{ll}
\mathrm{V}_{\mathrm{A}} & =\mathrm{V}_{\mathrm{B}}=\mathrm{V}_{\mathrm{C}}=1 \\
\mathrm{~V}_{\mathrm{e}} & =\mathrm{V}_{\mathrm{T}}-\mathrm{V}_{\mathrm{A}}-\mathrm{V}_{\mathrm{B}}-\mathrm{V}_{\mathrm{C}}
\end{array}
$$




$$
\begin{aligned}
& =47-1-1-1 \\
& =44
\end{aligned}
$$

7. Rata-rata jumlah kuadrat

Rata-rata kuadrat adalah dihitung dari pembagian jumlah kuadrat dengan derajat kebebasan.

$$
\begin{aligned}
& \mathrm{MS}_{\mathrm{A}}=\frac{\mathrm{SS}_{\mathrm{A}}}{\mathrm{V}_{\mathrm{A}}}=\frac{1}{1}=1 \\
& \mathrm{MS}_{\mathrm{B}}=\frac{\mathrm{SS}_{\mathrm{B}}}{\mathrm{V}_{\mathrm{B}}}=\frac{1}{1}=1 \\
& \mathrm{MS}_{\mathrm{C}}=\frac{\mathrm{SS}_{\mathrm{C}}}{\mathrm{V}_{\mathrm{C}}}=\frac{1}{1}=1 \\
& \mathrm{MS}_{\mathrm{e}}=\frac{\mathrm{SS}_{\mathrm{e}}}{\mathrm{V}_{\mathrm{e}}}=\frac{81}{44}=1,84
\end{aligned}
$$

8. Perhitungan F-hitung

$$
\begin{aligned}
& \mathrm{F}_{\mathrm{A}}=\frac{\mathrm{MS}_{\mathrm{A}}}{\mathrm{MS}_{\mathrm{e}}}=\frac{1}{1,84}=0,54 \\
& \mathrm{~F}_{\mathrm{B}} \quad=\frac{\mathrm{MS}_{\mathrm{B}}}{\mathrm{MS}_{\mathrm{e}}}=\frac{1}{1,84}=0,54 \\
& \mathrm{~F}_{\mathrm{C}} \quad=\frac{\mathrm{MS}_{\mathrm{C}}}{\mathrm{MS}_{\mathrm{e}}}=\frac{1}{1,84}=0,54
\end{aligned}
$$

Hasil perhitungan di atas digunakan untuk menggambarkan Analisis Varians seperti pada tabel 6 .

Tabel 6. Analisis Varians

\begin{tabular}{ccccc}
\hline Faktor & SS & V & MS & F-hitung \\
\hline A & 1 & 1 & 1 & 0,54 \\
B & 1 & 1 & 1 & 0,54 \\
C & 1 & 1 & 1 & 0,54 \\
Error & 81 & 44 & 1,84 & 1 \\
St & 84 & 47 & - & - \\
\hline
\end{tabular}

Sumber : pengolahan data
Strategi pooling up dilakukan untuk menentukan faktor yang paling berpengaruh secara signifikan pada kualitas produk. Pooling up menggunakan perhitungan dan tabel anova dengan dibagi dua tahap yaitu pooling parsial I ( $\mathrm{Ms}_{\text {hitung }} \leq$ $\left.\mathrm{Ms}_{\text {error }}\right)$ dan pooling parsial II $\left(\mathrm{F}_{\text {hitung }} \leq\right.$ $\left.\mathrm{F}_{\text {tabel }}\right)$.

\section{Pooling parsial I}

Pada pooling parsial I dilakukan untuk faktor dengan ketentuan nilai $\left(\mathrm{Ms}_{\text {hitung }} \leq \mathrm{Ms}_{\text {error }}\right)$. Dari tabel 4.13. yang dipooled adalah faktor $\mathrm{B}$ karena nilai $\mathrm{Ms}_{\text {hitung }}$ lebih kecil dari nilai $\mathrm{Ms}_{\text {error }}(1,84)$. Untuk faktor yang tidak dipooled yaitu faktor A dan $\mathrm{C}$ dilakukan perhitungan $\mathrm{Ss}_{\text {faktor }}$ dan $\mathrm{F}_{\text {hitung }}$ yang baru.

a. Pooled faktor B

$$
\begin{aligned}
\mathrm{Ss}_{\text {pooled I }} & =\mathrm{Ss}_{\text {error }}+\mathrm{Ss}_{\mathrm{B}} \\
& =81+1 \\
& =82 \\
& =\mathrm{V}_{\mathrm{e}}+\mathrm{V}_{\mathrm{B}} \\
& =44+1 \\
\mathrm{~V}_{\text {pooled I }} & =45 \\
\mathrm{Ms}_{\text {pooled I }}=\mathrm{V}_{\text {el }} & =\frac{\text { Ss pooled I }}{\mathrm{V} \text { pooled I }} \\
& =\frac{82}{45} \\
& =1,82
\end{aligned}
$$

b. Non pooled faktor A dan C

1. Nilai F-hitung

$$
\begin{aligned}
& \mathrm{F}_{\mathrm{A}}=\frac{\mathrm{MS}_{\mathrm{A}}}{\mathrm{MS}_{\text {pooled } \mathrm{I}}}=\frac{1}{1,82}=0,55 \\
& \mathrm{~F}_{\mathrm{C}}=\frac{\mathrm{MS}_{\mathrm{C}}}{\mathrm{MS}_{\text {pooled I }}} \quad=\frac{1}{1,82}=0,55
\end{aligned}
$$

c. Nilai SS' 


$$
\mathrm{Ss}{ }_{\mathrm{A}}=\mathrm{Ss}_{\mathrm{A}}-\left(\mathrm{V}_{\mathrm{A}} \times \mathrm{V}_{\mathrm{el}}\right)
$$

\begin{tabular}{ccccccc}
\hline Faktor & Pooled & SS & V & MS & $\begin{array}{c}\text { F- } \\
\text { hitung }\end{array}$ & SS' \\
& & \multicolumn{5}{c}{} \\
\hline A & - & 1 & 1 & 1 & 0,55 & $-0,82$ \\
B & Y & - & - & - & - & - \\
C & - & 1 & 1 & 1 & 0,55 & $-0,82$ \\
Error & - & 81 & 45 & 1,82 & - & 85,64 \\
St & - & 84 & 47 & - & - & 84 \\
\hline
\end{tabular}

$$
\begin{aligned}
& =1-(1 \times 1,82) \\
& =-0,82 \\
\mathrm{Ss}^{\prime}{ }_{C} & =\mathrm{Ss}_{\mathrm{C}}-\left(\mathrm{V}_{\mathrm{C}} \times \mathrm{V}_{\mathrm{el}}\right) \\
& =1-(1 \times 1,82) \\
& =-0,82
\end{aligned}
$$$$
\text { Ss }{ }_{\text {pooled }}=\mathrm{S}_{\mathrm{T}}-\mathrm{Ss}{ }_{\mathrm{A}}-\mathrm{Ss}_{\mathrm{C}}
$$$$
=84-(-0,82)-(-
$$

$$
=85,64
$$

Tabel 7. Tabel Hasil Pooling Parsial I

Sumber : pengolahan data

Pada tabel di atas dapat diketahui bahwa tidak terdapat faktor-faktor yang $\mathrm{Ms}_{\text {hitung }} \leq$ $\mathrm{Ms}_{\text {error }}$ sehingga pooling parsial I selesai.

\section{Pooling Parsial II}

Pada pooling parsial II, dilakukan untuk faktor-faktor dengan nilai $\mathrm{F}_{\text {hitung }} \leq$ $F_{\text {tabel }}$ dengan tingkat kepercayaan $95 \%$. Nilai $F_{\text {tabel }}$ dapat dilihat pada lampiran tabel statistik. Tabel $\mathrm{F}$ untuk $\mathrm{V}_{1}=1, \mathrm{~V}_{2}=$ 45 adalah $F_{0,05(1,45)}=4,06$. Faktor yang dipool pada tahap ini adalah faktor A dan $\mathrm{C}$ karena nilai $\mathrm{F}_{\text {hitung }} \leq \mathrm{F}_{\text {tabel }}$. Sedangkan faktor B dilakukan perhitungan $\mathrm{Ss}_{\text {faktor }}$ dan $\mathrm{F}_{\text {hitung }}$ yang baru.

a. Pooled faktor A dan C

$$
\begin{aligned}
\mathrm{Ss}_{\text {pooled II }} & \mathrm{Ss}_{\text {error }}+\mathrm{Ss}_{\mathrm{A}}+\mathrm{Ss}_{\mathrm{C}} \\
= & 81+1+1 \\
& =83 \\
\mathrm{~V}_{\text {pooled II }} & =\mathrm{V}_{\mathrm{e}}+\mathrm{Ss}_{\mathrm{A}}+\mathrm{Ss}_{\mathrm{C}} \\
& =45+1+1 \\
& =47 \\
\mathrm{Ms}_{\text {pooled II }} & =\mathrm{V}_{\mathrm{el}}=\frac{\text { Ss pooled II }}{\mathrm{V} \text { pooled II }} \\
& =\frac{83}{47}
\end{aligned}
$$

\begin{tabular}{lllllll}
\hline Faktor & Pooled & SS & V & MS & $\begin{array}{l}\text { F- } \\
\text { hitung }\end{array}$ & SS' \\
\hline A & Y & - & - & - & - & - \\
B & - & 1 & 1 & 1 & 0,568 & $-0,76$ \\
C & Y & - & - & - & - & - \\
Error & - & 81 & 47 & 1,76 & 1 & 84,76 \\
St & - & 84 & 48 & - & - & 84 \\
\hline \multicolumn{5}{c}{$=1,76$} \\
\end{tabular}

b. Pooled faktor B

1. Nilai F-hitung

$$
\begin{aligned}
& \mathrm{F}_{\mathrm{B}}=\frac{\mathrm{MS}_{\mathrm{B}}}{\mathrm{MS}_{\text {Pooled II }}}=\frac{1}{1,76}= \\
& 0,568
\end{aligned}
$$

2. Nilai SS'

$$
\mathrm{Ss}_{\mathrm{B}}=\mathrm{Ss}_{\mathrm{B}}-\left(\mathrm{V}_{\mathrm{B}} \times \mathrm{V}_{\mathrm{el}}\right)
$$

$$
\begin{aligned}
& =1-(1 \times 1,76) \\
& =-0,76
\end{aligned}
$$

$$
\begin{aligned}
\mathrm{Ss}_{\text {pooled }} & =\mathrm{S}_{\mathrm{T}}-\mathrm{Ss}^{\prime}{ }_{\mathrm{B}} \\
& =84-(-0,76) \\
& =84,76
\end{aligned}
$$

Tabel 8. Tabel Hasil Pooling Parsial II 
Sumber : pengolahan data

Berdasarkan Pooling Parsial I dan II, dapat diketahui bahwa faktor yang paling berpengaruh terhadap kadar ALB adalah faktor $\mathrm{A}$ dan $\mathrm{C}$ yaitu tekanan perebusan dan Waktu perebusan.

4.2.2.4. Pemilihan Kombinasi Level Faktor Optimal

Untuk mengetahui seberapa besar kontribusi yang diberikan masing-masing faktor, maka persen kontribusi masingmasing faktor dihitung dengan rumus :

$$
\begin{array}{ll}
\rho & =\frac{\mathrm{SS}_{\text {faktor }}}{\mathrm{S}_{\mathrm{T}}} \times 100 \% \\
\rho_{A} & =\frac{1}{84} \times 100 \%=1,19 \% \\
\rho_{B} & =\frac{1}{84} \times 100 \%=1,19 \% \\
\rho_{C} & =\frac{1}{84} \times 100 \%=1,19 \%
\end{array}
$$

Telah diketahui faktor-faktor yang berpengaruh terhadap kadar ALB yang paling optimum adalah sebagai berikut:

1. Faktor A level 1 (tekanan perebusan 2,0 torr).

2. Faktor C level 1 (waktu pada proses perebusan $50 \mathrm{~min}$ ).

3. Faktor B level 2 (temperatur perebusan $105^{\circ} \mathrm{C}$ ).

Dari setting yang ada diharapkan hasil produksi TBS menjadi Refined Bleached Deodorized Palm Oil yang tidak sesuai dengan standar dapat ditekan seminimal mungkin sesuai target karakteristik yang ingin dicapai yaitu Smaller the Better.

\section{SIMPULAN}

Dengan menggunakan metode Taguchi dalam usaha perbaikan kualitas pada PT. XYZ , maka dapat diambil kesimpulan yaitu :

Dalam proses pengendalian kualitas Refined Bleached Deodorized Palm Oil diketahui bahwa faktor-faktor yang mempengaruhi kualitas Refined Bleached Deodorized Palm Oil adalah kadar asam lemak bebas, kadar warna dan kadar air. Sedangkan faktor yang menyebabkan penyimpangan terhadap kualitas Refined Bleached Deodorized Palm Oil yaitu tekanan pada perebusan, temperatur perebusan dan waktu pada proses perebusan.Persen kontribusi dari faktorfaktor yang berpengaruh terhadap kualitas Refined Bleached Deodorized Palm Oil berdasarkan hasil pooling parsial adalah sebagai berikut :Kadar ALB Faktor A (tekanan pada perebusan): 1,19\% Faktor B (temperatur pada perebusan) : $1,19 \%$ Faktor C (waktu pada proses perebusan) : 1,19\% Kadar Warna Faktor A (tekanan pada perebusan) : $0,51 \%$ Faktor $\mathrm{B}$ (temperatur pada perebusan) : 0,51\% Faktor C (waktu pada proses perebusan) : 12,63\% Kadar Air Faktor C (tekanan pada perebusan) : 1,2\% Faktor A (temperatur pada perebusan) : 1,2\% Faktor C (waktu pada proses perebusan) : 1,2\% Kombinasi setting level yang optimal berdasarkan metode Taguchi adalah 
sebagai berikut : Kadar ALB Faktor A level 1 (tekanan perebusan 2,0 torr). Faktor B level 2 (temperatur pada perebusan 105oC). Faktor C level 1 (waktu pada proses perebusan $50 \mathrm{~min}$ ). Kadar air Faktor A level 1 (tekanan perebusan 2,0 torr). Faktor B level 2 (temperatur pada perebusan 105oC). Faktor C level 1 (waktu pada proses perebusan $50 \mathrm{~min}$ ).

\section{DAFTAR PUSTAKA}

Besterfield, Dale H. 1994, Quality Control, Fifth Edition, Prentice-Hall International, Inc., Englewood Cliffs, New Jersey

Ernawati. 2014, Aplikasi Metode Taguchi Dalam Pengendalian Kualitas Produksi, Jurnal Teknosains Vol. 8 No. 2, Fakultas Teknologi Dan Sains, UIN Alauddin Makasar

Fauzy, Akhmad. 2008, Statistik Industri, PT. Gelora Aksara Pratama, Jakarta Ginting, Rosnani. 2007, Sistem Produksi,. Graha Ilmu, Yogyakarta

Hartono, M, 2000. Perancangan Kualitas Dengan Metode Taguchi, Jurnal Bistek Politeknik Unibraw, 8(12).

Hartono, M, 2001. Quality by Design Dengan Metode Taguchi, Konsep Dan Perkembangannya,Jurnal Industri Universitas

Muhammadiyah Malang, Mangoensoekarjo, S dan H. Semangun. 2003, Manajemen
Agrobisnis Kelapa Sawit, Gadjah Mada University Press, Yogyakarta

Soejanto, Irwan. 2009, Desain Eksperimen Dengan Metode Taguchi, Edisi Pertama, Graha Ilmu, Yogyakarta Sudjana. 1997, Metoda Statistika, Edisi Keenam, Tarsito, Bandung

Sugiyono. 2013, Metode Penelitian Manajemen, Cetakan Ketiga, Alfabeta, Bandung

Suseno. 2013, Analisis Produksi Pada Mesin Speed Dengan Pendekatan Taguchi Untuk Mengurangi Cacat Produk Di PT Industri Sandang Nusantara, Jurnal Teknik Industri Vol. 3 No. 1 Fakultas Sains Dan Teknologi, Universitas Teknologi Yogyakarta

Telaumbanua, Adventhinus. 2013, Analisis Pengendalian Kualitas Dengan Pendekatan Metode Taguchi Pada PT. Asahan Crumb Rubber, e-Jurnal Teknik Industri 